\title{
Balsalazide Potentiates Parthenolide-Mediated Inhibition of Nuclear Factor- $\kappa$ B Signaling in HCT116 Human Colorectal Cancer Cells
}

\author{
Hyun-Young Kim ${ }^{1}$, Se-Lim Kim ${ }^{1,2}$, Young-Ran Park ${ }^{1,2}$, Yu-Chuan Liu ${ }^{1,2}$, Seung Young Seo ${ }^{1}$, \\ Seong Hun Kim ${ }^{1}$, In Hee Kim ${ }^{1}$, Seung Ok Lee ${ }^{1}$, Soo Teik Lee ${ }^{1,2}$, Sang Wook Kim ${ }^{1,2}$ \\ Department of Internal Medicine, Medical School of Chonbuk National University', Colon Carcinogenesis and Inflammation Laboratory, \\ Biomedical Research Institute of Chonbuk National University Hospital', Jeonju, Korea
}

Background/Aims: Balsalazide is an anti-inflammatory drug used in the treatment of inflammatory bowel disease. Balsalazide can reduce inflammatory responses via several mechanisms, including inhibition of nuclear factor- $\kappa \mathrm{B}(\mathrm{NF}-\kappa \mathrm{B})$ activity. Parthenolide (PT) inhibits NF- $\mathrm{B}$ and exerts promising anticancer effects by promoting apoptosis. The present investigated the antitumor effects of balsalazide, combined with PT, on NF- $\kappa B$ in a representative human colorectal carcinoma cell line, HCT116. Methods: We counted cells and conducted annexin-V assays and cell cycle analysis to measure apoptotic cell death. Western blotting was used investigate the levels of proteins involved in apoptosis. Results: PT and balsalazide produced synergistic anti-proliferative effects and induced apoptotic cell death. The combination of balsalazide and PT markedly suppressed

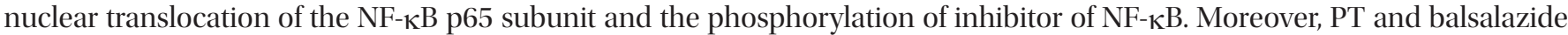
dramatically enhanced NF-кB p65 phosphorylation. Apoptosis, through the mitochondrial pathway, was confirmed by detecting effects on Bcl-2 family members, cytochrome c release, and activation of caspase- 3 and -8 . Conclusions: Combination treatment with PT and balsalazide may offer an effective strategy for the induction of apoptosis in HCT116 cells. (Intest Res 2015;13:233-241)

Key Words: Balsalazide; Parthenolide; NF-кB; Apoptosis; Colorectal neoplasms

\section{INTRODUCTION}

Sulfasalazine was developed by combining the antiinflammatory compound, 5-aminoslaicylic acid (5-ASA), with the antimicrobial agent, sulfapyridine. Although sulfasalazine has been shown to be effective for the treatment of moderate UC, its use is limited by the high risk of side ef-

Received September 1, 2014. Revised December 16, 2014.

Accepted December 29, 2014.

Correspondence to Sang-Wook Kim, Department of Internal Medicine,

Chonbuk National University Hospital, 20 Geonji-ro, Deokjin-gu, Jeonju 561-

712, Korea. Tel: +82-63-250-2302, Fax:+82-63-254-1609, E-mail: clickm@

jonu.ac.kr

Financial support: This study was supported by fund of Biomedical Research Institute, Chonbuk National University Hospital. Conflict of interest: None. fects. 5-ASA provides local anti-inflammatory effects in the colonic lumen and is utilized to treat moderate UC. ${ }^{1}$ These agents can effectively induce and maintain remission in UC and have been reported to play a limited role in the induction of remission in CD. Sulfa-free aminosalicylate agents that efficiently deliver large doses of pharmaceutically active sulfasalazine into colonic lesions, while reducing systemic toxicity, include olsalazine, balsalazide, and melsalazine; the compounds showed no difference in efficacy or safety, as compared with various dosage forms of oral 5-ASA. ${ }^{2,3}$ Balsalazide, an azo bond compound of 5-ASA and 4-aminobenzoyl- $\beta$-alanine, has been approved by the Food and Drug Administration, USA, for use in mild and moderate active UC. The covalent bonds between 5-ASA and 4-aminobenzoyl- $\beta$-alanine in balsalazide are hydrolyzed by colonic

\footnotetext{
๑ Copyright 2015. Korean Association for the Study of Intestinal Diseases. All rights reserved.

This is an Open Access article distributed under the terms of the Creative Commons Attribution Non-Commercial License (http://creativecommons.org/licenses/by-nc/4.0)

which permits unrestricted non-commercial use, distribution, and reproduction in any medium, provided the original work is properly cited.
} 
bacteria, facilitating intestinal drug release; this compound is particularly effective in the colon, triggering anti-inflammatory responses through various mechanisms that include suppression of tumor necrosis factor-alpha, interleukin (IL)1, IL-2, IL-8, and nuclear factor kappa-B (NF- $\kappa \mathrm{B}) .{ }^{4,5}$

Parthenolide (PT) is present in extracts of feverfew, and has long been utilized as a folk remedy for the treatment of fever, headache, inflammation, and arthritis; it was also reported to elicit anti-inflammatory effects via suppression of NF- $\kappa \mathrm{B}$ and IL-1. ${ }^{6-12}$ Some previous studies demonstrated that PT had anti-cancer activities; these included NF-кBmediated suppression of mitochondrial function, as well as inhibition of cell growth and angiogenesis. ${ }^{11,13-15}$ However, to our knowledge, no study has reported the effects of coadministration of balsalazide and PT on colon cancer cells.

In the present study, we investigated how exposure to both balsalazide and PT affected apoptosis and related mechanisms in human colon cancer cells.

\section{METHODS}

\section{Reagents}

Fetal bovine serum, penicillin/streptomycin, RPMI 1640 culture medium, trypsin EDTA, and annexin-V FITC were acquired from Invitrogen (Eugene, OR, USA). 3-(4,5-dimethylthiazol-2-yl)-2,5-diphenyltetrazolium bromide (MTT), sodium pyruvate, and dimethyl sulfoxide were from SigmaAldrich (St. Louis, MO, USA) and balsalazide was obtained from Chong Kun Dang Pharm (Seoul, Korea). PT was from Calbiochem (San Diego, CA, USA) and all primary and secondary antibodies used in western blotting analyses were from Santa Cruz Biotechnology (Santa Cruz, CA, USA).

\section{Cell Culture}

HCT116 human colorectal cancer cells were obtained from the American Type Culture Collection (CCL-247 ${ }^{\mathrm{TM}}$, Rockville, MD, USA). HCT116 cells were incubated at $37^{\circ} \mathrm{C}$ with $5 \% \mathrm{CO}_{2}$ in RPMI 1640 supplemented with $10 \%$ fetal bovine serum, $2 \mathrm{mM}$ L-glutamine, $2 \mathrm{U} / \mathrm{mL}$ penicillin $\mathrm{G}$, and $2 \mathrm{mg} / \mathrm{mL}$ streptomycin. Cells were treated with PT and/or balsalazide in serum free medium, as indicated. In experiments involving caspase inhibition, cells were treated with a pan-caspase inhibitor (Z-VAD-FMK; $10 \mu \mathrm{M}$ ) for 1 hour prior to treatment with PT and balsalazide.

\section{Measurement of Cell Viability}

HCT116 cells were seeded in a 24-well cell culture plate $\left(3 \times 10^{4}\right.$ cells/well) and incubated for 24 hours. PT and/ or balsalazide were added to the cells and incubated for a further 24 hours. The culture medium was removed and $1 \times$ trypsin-EDTA was added to detach the cells from the dish, followed by $500 \mu \mathrm{L}$ phosphate buffered saline (PBS) to harvest the cells, which were then centrifuged at 1,000 rpm for 5 minutes. The supernatant was removed and $1 \mathrm{~mL}$ PBS was added, followed by mixing. The resulting cell suspension was mixed with the same volume of $0.5 \%$ trypan blue (Gibco, NY, USA) and $10 \mu \mathrm{L}$ of this mixture was placed in a hemocytometer in order to count live cells utilizing an inverted microscope (Carl Zeiss, Oberkochen, Germany).

\section{Analysis of Apoptosis}

Apoptosis was measured using an apoptosis kit (Invitrogen) in accordance to the instructions provided by the manufacturer. In brief, the HCT116 cells were diluted to a concentration of $2 \times 10^{5}$ cells $/ \mathrm{mL}$, seeded into a 6 -well plate, and incubated in an incubator at $37^{\circ} \mathrm{C}$ with $5 \% \mathrm{CO}_{2}$. When the cells had attached, PT and/or balsalazide were added and incubated for 24 hours in the incubator. The treated cells were then washed with PBS and detached using $85 \mu \mathrm{L}$ of the kit binding buffer. Annexin V-FITC $(10 \mu \mathrm{L})$ and propidium iodide (PI; $5 \mu \mathrm{L}$ ) were added and incubated at room temperature for 15 minutes. Subsequently, $400 \mu \mathrm{L}$ binding buffer was added and fluorescence was measured using the BD LSR flow cytometer (Becton Dickinson, San Jose, CA, USA).

In addition, in order to monitor changes in the cell cycle, HCT116 cells treated with PT and/or balsalazide were harvested and suspended in $75 \%$ ethanol, followed by 24 -hour fixation in a refrigerator. Fixed cells were stained in $50 \mu \mathrm{g} /$ $\mathrm{mL}$ PI solution for 30 minutes at $37^{\circ} \mathrm{C}$ and RNase A (100 $\mu \mathrm{g} /$ $\mathrm{mL}$ ) was added to completely remove intracellular RNA. After washing cells with PBS, the cell cycle was analyzed using the BD LSR flow cytometer (Becton Dickinson).

\section{Western Blotting}

Western blotting analysis was performed in order to identify changes in protein expression in the presence of PT and/or balsalazide. To examine the translocation of the NF$\kappa \mathrm{B}$ p65 subunit, the cytosolic and nuclear fractions were separated prior to protein extraction. After treatment with PT and/or balsalazide for 24 hours, cells were washed with ice-cold PBS (pH 7.4) followed by centrifugation at 1,200 
rpm for 5 minutes to collect the cells. The cytosolic fraction buffer (10 mM HEPES pH 7.9, $1.5 \mathrm{mM} \mathrm{MgCl}_{2}, 10 \mathrm{mM} \mathrm{KCl}, 0.5$ $\mathrm{mM}$ dithiothreitol, $0.5 \mathrm{mM}$ phenylmethylsulphonylfluoride, $0.4 \%$ Nonidet $\mathrm{P}-40$, and $1 \times$ protease inhibitor cocktail) was utilized to lyse the cells, followed by centrifugation at 13,000 rpm for 1 minute. The resulting supernatant was utilized as the cytosolic fraction, while the resulting cellular pellet was washed twice with cold PBS and then suspended in the nuclear fraction buffer (20 mM HEPES pH 7.9, $420 \mathrm{mM} \mathrm{NaCl}$, $1.5 \mathrm{mM} \mathrm{MgCl}_{2}, 0.2 \mathrm{mM}$ EDTA, $0.5 \mathrm{mM}$ dithiothreitol, $0.5 \mathrm{mM}$ phenylmethylsulphonylfluoride, and $1 \times$ protease inhibitor cocktail) and vortexed strongly over 30 minutes. This was then centrifuged at 13,000 rpm for 30 minutes. In addition, a total cell lysate was prepared using RIPA buffer (Invitrogen), in accordance with the manufacturer's instructions. The proteins were denatured at $95^{\circ} \mathrm{C}$, separated by sodium dodecyl sulfate-polyacrylamide gel electrophoresis at a voltage of 100 $\mathrm{V}$, and transferred onto a polyvinylidene difluoride membrane (Biorad, CA, USA). The membrane was incubated

A

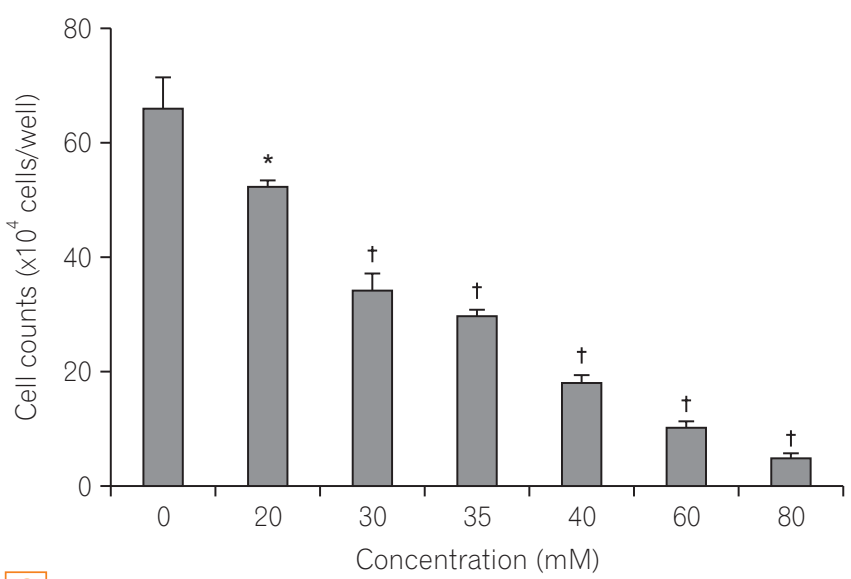

C

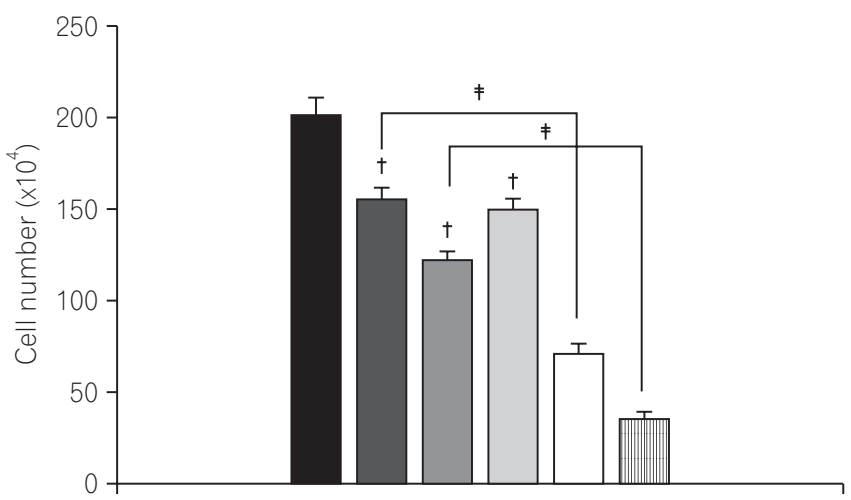

with 5\% non-fat dried milk for 1 hour in order to inhibit nonspecific binding, followed by overnight incubation with a primary antibody: anti-mouse-p65 (sc-8008), anti-rabbit phospho-p65 (Ser 536; sc-33020), anti-mouse phospho-inhibitor of NF- $\kappa \mathrm{B}$ alpha $\left(\mathrm{I}_{\kappa} \mathrm{B} \alpha\right)$ (sc-8404), anti-rabbit caspase-3 (sc7148), anti-mouse caspase-8 (sc-73526), anti-mouse Bcell lymphoma-extra large (Bcl-xL) (sc-8392), anti-rabbit Bcell lymphoma 2 (Bcl-2) (sc-783), anti-goat cleaved Bid (sc34325), anti-mouse Bcl-2-associated X protein (BAX) (sc7480), anti-mouse cytochrome c (sc-65396), or anti-rabbit actin (sc-1616). The membrane was subsequently incubated for 1 hour with the relevant secondary antibody conjugated with horseradish peroxidase (HRP): donkey anti-goat IgGHRP (sc-2020), goat anti-rabbit IgG-HRP (sc-2004), or goat anti-mouse IgG-HRP (sc-2005). Protein bands were visualized using ECL prime (Amersham, PA, USA) and confirmed using the Luminescent Image Analyzer (LAS-3000; Fuji Film, Tokyo, Japan).

B

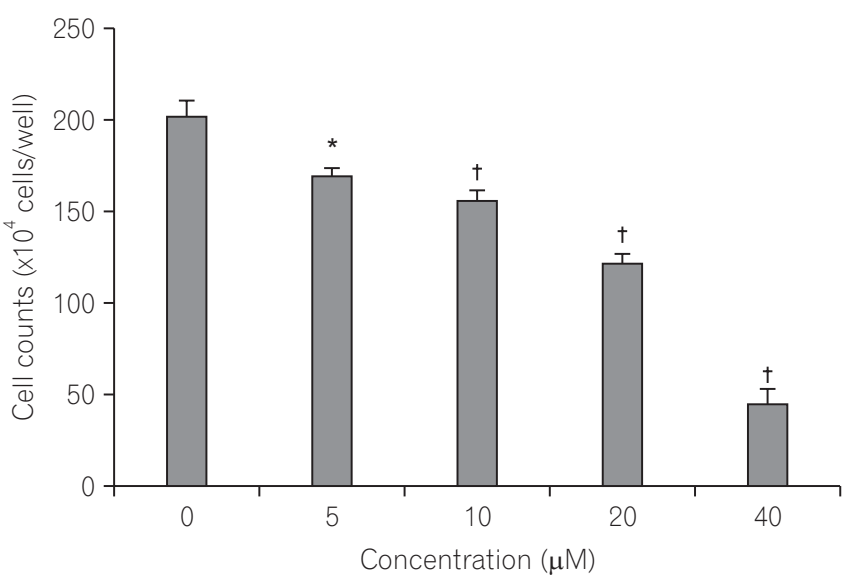

Fig. 1. Inhibitory effects of parthenolide (PT) and balsalazide on cell growth. HCT116 cells were exposed to the indicated concentrations of (A) balsalazide, (B) PT, or (C) $20 \mathrm{mM}$ balsalazide and 10 or $20 \mu \mathrm{M}$ PT for $24 \mathrm{~h}$. The data represent the mean cell counts \pm the standard error of the mean of three independent experiments. ${ }^{*} P<0.05,{ }^{\dagger} P<0.001$, as compared to control and ${ }^{\dagger} P<0.05$, as compared to PT-treated cells. 


\section{Statistical Analysis}

All experimental results were expressed as mean \pm SEM and groups were compared using Student's $t$-test. A differ- ence was considered statistically significant if the $P$-value was $<0.05$. All statistical analyses were carried out using Sigma Plot version 12 (Systat Software, San Jose, CA, USA).
A
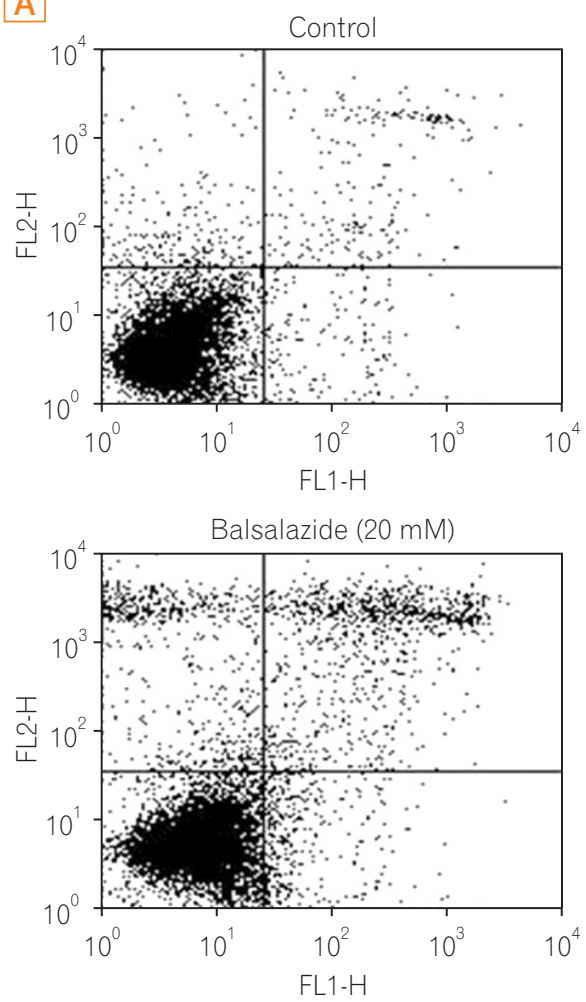

B
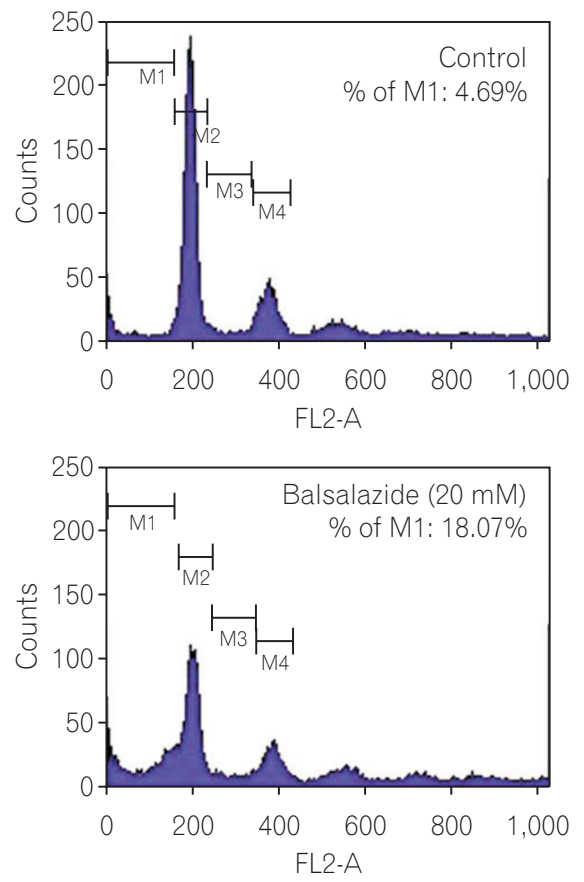
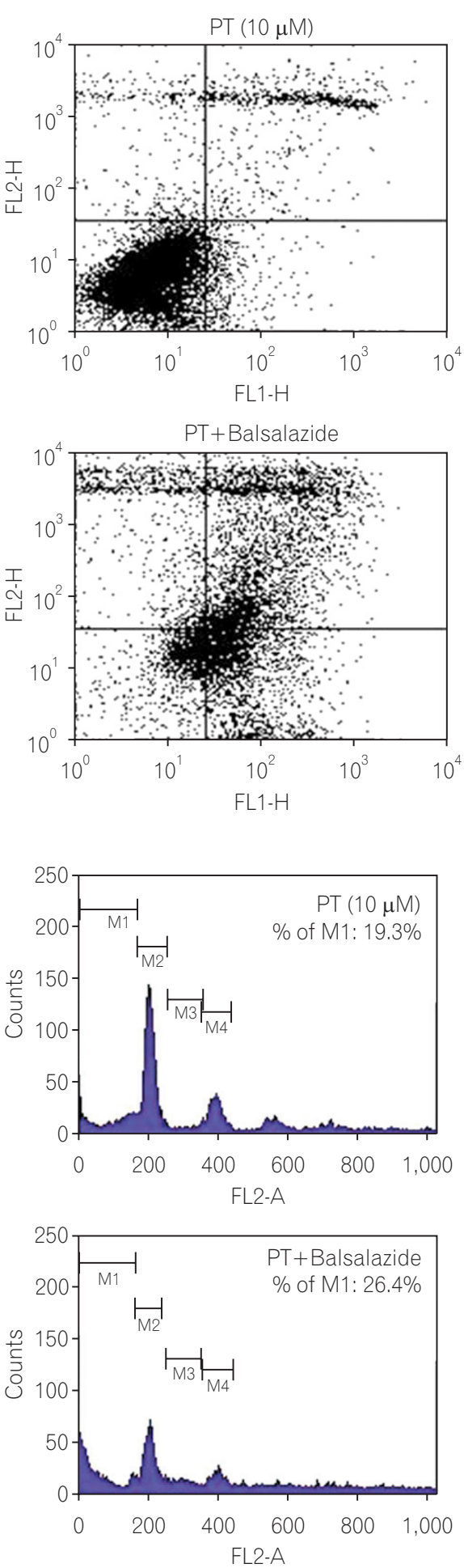

Fig. 2. Apoptotic cell death was induced by parthenolide (PT) and balsalazide. (A) After treatment with PT and/or balsalazide for $24 h$, cells were harvested and stained with annexin-V FITC/propidium iodide (PI). (B) Cell cycle modification induced by combination treatment. After treatment with PT and/or balsalazide for $24 h$, cells were harvested, fixed, and stained with PI. The percentage of the population in sub-G1 is reported in each histogram and the total number of events analyzed for each condition was 10,000 . 


\section{RESULTS}

\section{Synergistic Cytotoxic and Growth Inhibitory Effects of Balsalazide and PT in HCT116 Cells}

HCT116 cell viability was analyzed following 24-hour treatment with various concentrations of balsalazide; cell viability decreased as the concentration increased up to $80 \mathrm{mM}$, confirming a concentration-dependent effect on the viability of HCT116 cells (Fig. 1A). Similarly, cells exposed to PT showed a concentration-dependent decrease in cell viability up to the highest concentration employed, $40 \mu \mathrm{M}$ (Fig. 1B). In the presence of PT and balsalazide, however, the changes in HCT116 cell viability were more pronounced, indicating that these compounds produced synergistic suppression of cancer cell viability (PT treatment only: $77.54 \pm 2.80 \%$ cell viability; balsalazide treatment only: $81.77 \pm 3.90 \%$ cell viability; PT and balsalazide treatment: $33.97 \pm 4.74 \%$ cell viability; Fig. 1C).

\section{Induction of Apoptotic Cell Death in the Presence of Balsalazide and PT}

Annexin V/PI staining was utilized to investigate apoptotic cancer cell death in the presence of balsalazide and PT. Briefly, cells stained with annexin- $V$ were categorized into live cells (lower left [LL]; Fig. 2A); early apoptotic cells (lower right [LR]); late apoptotic cells (upper right [UR]); and necrotic cells (upper left [UL]) and the ratio of these cells can be analyzed using flow cytometry. In the negative control cells (no treatment), UL, UR, LL, and LR contained $2.40 \%, 2.47 \%, 90.37 \%$, and $4.76 \%$, respectively. In the PTtreated cells, UL, UR, LL, and LR were $4.43 \%, 7.35 \%, 79.50 \%$, and $8.72 \%$, respectively. The percentages of cells in the UL, UR, LL, and LR were $9.88 \%, 10.40 \%, 73.37 \%$, and $6.35 \%$ in the balsalazide treatment group. Lastly, after exposure to both PT and balsalazide, UL, UR, LL, and LR contained $12.34 \%$, $31.98 \%, 13.63 \%$, and $42.05 \%$ of the cells, respectively. Notably, the UR area (containing late apoptotic cells) was about $2 \%$ in the negative control group as compared with $7-10 \%$ in the PT- or balsalazide-treated cells. This induction of apoptotic cell death was significantly elevated in the co-administration group, where $32 \%$ of the cells were in the UR area (Fig. 2A).

Changes in the cell cycle in cancer cells provide important information for the interpretation and understanding of the mechanisms involved in apoptotic cell death. The present study therefore utilized flow cytometry in order to monitor changes in the cell cycle, as well as the rate of apoptotic cell death, in response to PT and/or balsalazide. In the analysis of the cell cycle data, cells in M1 indicate the sub-G1 whilst M2 and S mean G0/G1 and G2/M, respectively. In cells exposed to PT or balsalazide alone, relatively higher sub-G1 arrest was observed, as compared to the control cells (the negative control group: 4.69\%; PT treatment only: $19.31 \%$; balsalazide treatment only: 18.07\%); this feature was further increased following exposure to PT and balsalazide, when the population of sub-G1 cells was $26.4 \%$ (Fig. 2B).

\section{NF- $\kappa$ B Modulation by Balsalazide and PT}

We prepared nuclear and cytosolic fractions in order to investigate the effects of balsalazide and PT on nuclear translocation of NF- $\mathrm{KB}$ using western blotting; proteins pres-
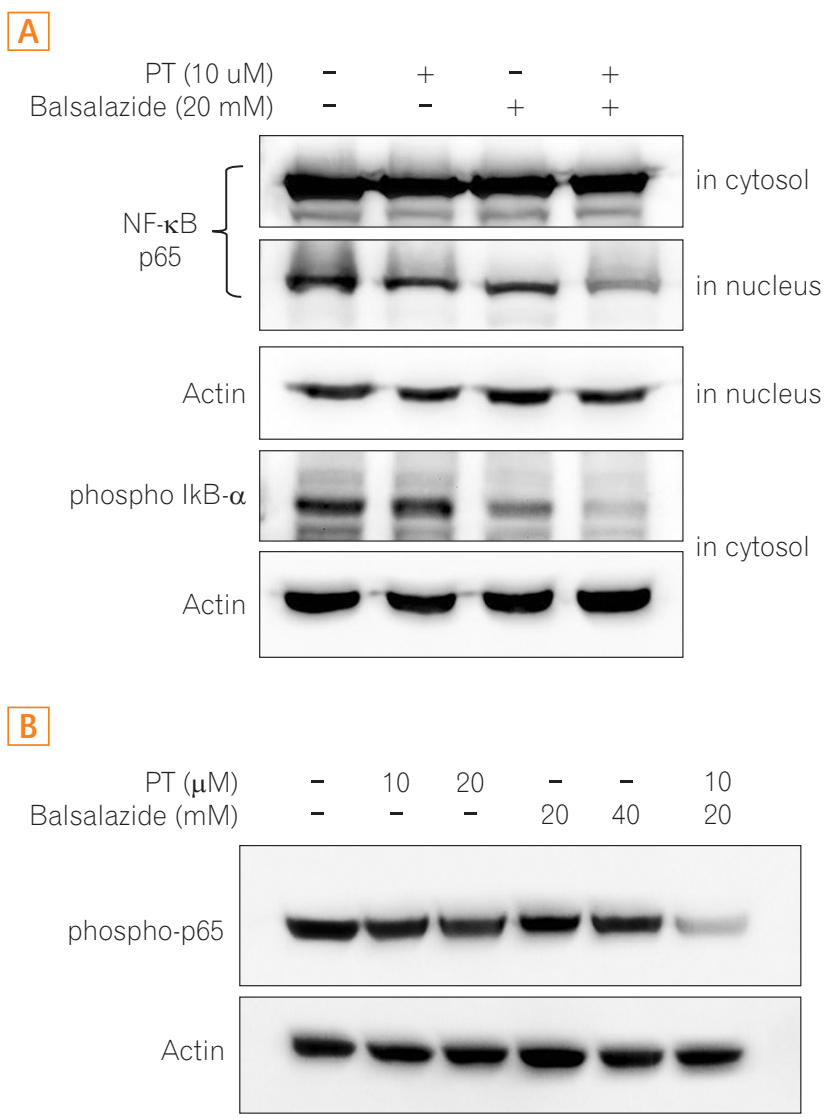

Fig. 3. Down-regulation of nuclear factor-kappa $B(N F-\kappa B)$ signaling by parthenolide (PT) and balsalazide. (A) Nuclear and cytosolic protein extracts were prepared from HCT116 cells treated with PT, balsalazide, or PT and balsalazide for $24 \mathrm{~h}$. Combined balsalazide and PT markedly sup-

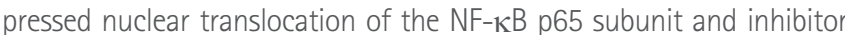
of NF- $\mathrm{B}$ alpha $\left({ }_{\kappa} \mathrm{B}-\alpha\right)$ phosphorylation. (B) Total protein extracts were prepared from HCT116 cells treated with PT (10,20 $\mu \mathrm{M})$, balsalazide (20, $40 \mathrm{mM}$ ), or both (10 $\mu \mathrm{M}$ PT plus $20 \mathrm{mM}$ balsalazide) for $24 \mathrm{~h}$. Combined balsalazide and PT dramatically suppressed p65 phosphorylation. Actin was used as the loading control. 
ent in the cytosol and nucleus were separated and analyzed using western blotting. This analysis observed no change in cytosolic proteins, although co-administration of PT and balsalazide significantly reduced the expression of p65, as compared to that observed in cells treated with PT or balsalazide alone (Fig. 3A, first panel). In addition, phosphorylation, ubiquitination, and hydrolysis of IкB- $\alpha$ are known to play important roles in activating NF-кB. The present study therefore analyzed phosphorylated $\mathrm{I}_{\kappa} \mathrm{B}-\alpha$ levels by western blotting following treatment with PT and/or balsalazide. These results indicated that exposure to these compounds significantly lowered the protein levels of phosphorylated $\mathrm{I}_{\kappa} \mathrm{B}-\alpha$, as compared to the levels observed in the single treatment groups (Fig. 3A, second panel).

As compared to simple translocation of p65 without phosphorylation, phosphorylation of p65 triggers strong

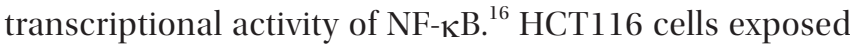
to PT showed a concentration-dependent reduction in the levels of phospho-p65; however, no noticeable changes were observed in cells treated with balsalazide. Notably, the phospho-p65 level was significantly decreased in cells treated with both PT and balsalazide (Fig. 3B).

\section{Changes in Caspase Activation in the Presence of Balsalazide and PT}

Caspases are important factors in the regulation of apoptotic cell death and are present as full-length inactive forms that are activated by cleavage in the presence of pro-

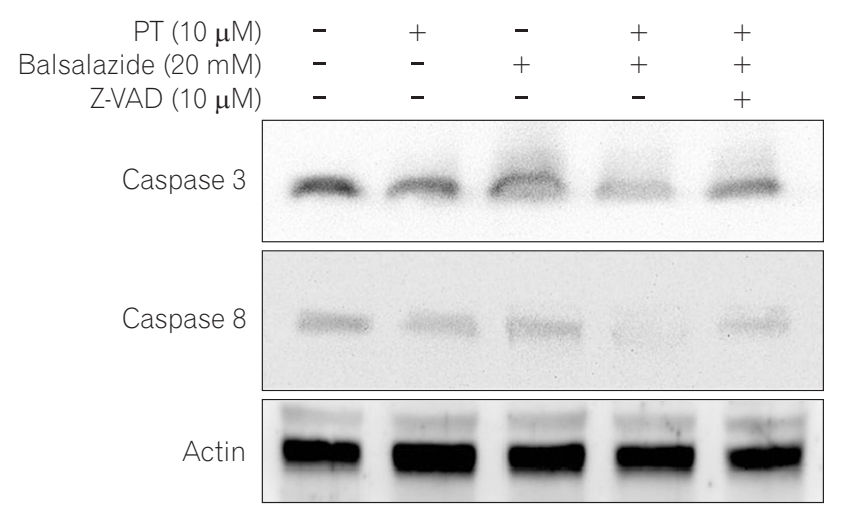

Fig. 4. Down-regulation of caspases by parthenolide (PT) and balsalazide. HCT116 cell lysates were prepared after treatment with PT, balsalazide, or PT and balsalazide for $24 \mathrm{~h}$ and then analyzed by western blotting with caspase- 3 or caspase- 8 antibodies. Combined treatment reduced the levels of full length caspase- 3 and caspase-8. However, caspase- 3 and caspase- 8 did not change when cells were pre-treated with a pan-caspase inhibitor (Z-VAD-FMK). Actin was used as the loading control. apoptotic signals. ${ }^{17}$ Therefore, western blotting analysis was performed to investigate the effects of PT and balsalazide on caspase activity (Fig. 4). The full-length forms of caspase-3 and -8 were analyzed and similar protein levels were found in the negative control cells and in cells treated with either PT or balsalazide; co-administration of these compounds significantly decreased the expression of caspase-3 and -8. To elucidate the mechanism(s) involved, cells were treated with the pan-caspase inhibitor, Z-VAD-FMK, and then exposed to PT and balsalazide. We found that the levels of caspase-3 and - 8 were restored by pre-treatment with Z-VADFMK (Fig. 4).

\section{Modulation of Bcl-2 Family Members and Cytoch- rome c}

Bcl-2 family proteins modulate mitochondrial membrane permeability; they are either present in mitochondrial membranes or translocate to the membranes in response to proapoptotic signals, thereby controlling apoptotic cell death. ${ }^{18}$ To investigate the apoptotic mechanism induced by coadministration of PT and balsalazide, and the effects on protein expression of Bcl-2 family members, western blotting was performed. As depicted in Fig. 5, simultaneous exposure of HCT116 to PT and balsalazide significantly lowered the protein levels of anti-apoptotic Bcl-2 family proteins (Bcl-XL,

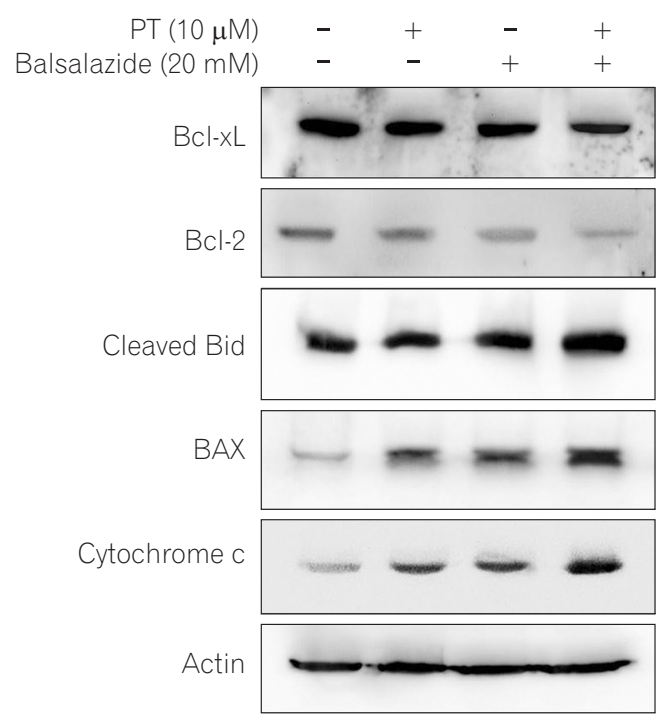

Fig. 5. Levels of apoptosis-associated proteins following treatment with parthenolide (PT) and balsalazide. HCT116 cell lysates were prepared after treatment with PT, balsalazide, or PT and balsalazide for $24 \mathrm{~h}$ and analyzed by western blotting using B-cell lymphoma 2 (Bcl-2), B-cell lymphoma-extra large ( $\mathrm{Bcl}-\mathrm{xL}), \mathrm{Bid}, \mathrm{Bcl}-2$-associated $\mathrm{X}$ protein (Bax), and cytochrome $\mathrm{c}$ antibodies. Actin was used as the loading control. 
and Bcl-2) and increased the levels of cleaved Bid, BAX, and cytochrome c (Fig. 5).

\section{DISCUSSION}

In contrast to sporadic colorectal cancers that are mainly caused by genetic factors, colitis-associated colon cancers are mostly associated with inflammatory bowel disorders; it is understood that chronic inflammation of the colonic epithelium can induce distinct types of colitis-associated colon cancers. To be specific, sporadic colorectal cancers, accounting for $65-85 \%$ of all colorectal cancers, develop through the 'adenoma-cancer' pathway, while colitis-associated colon cancers utilize the 'inflammation-dysplasia-cancer' pathway. ${ }^{19}$ It was therefore suggested that modulation of inflammation might be an effective approach to the prevention of colitis-associated colon cancers and in 1994, the incidence of colitis-associated colon cancers was reduced in UC patients treated with sulfasalazine, a 5-ASA derivative. ${ }^{20}$

It was also demonstrated that 5-ASA and its derivatives (1) impaired Wnt/ $\beta$-catenin signaling pathways; (2) activated peroxisome proliferator activated receptor gamma, which inhibits formation of cancer cells; (3) inhibited NF- $\kappa B$ activity; and (4) suppressed oxidative damage and DNA mutations. ${ }^{21}$ Recent studies have not shown statistically significant inhibitory effects of 5-ASA on colon cancer formation, making this a controversial approach to colon cancer prevention and induction of apoptotic cell death in colon cancer cells. ${ }^{22}$

To our knowledge, no previous studies have investigated the efficacy and underlying molecular mechanisms of combination balsalazide and PT chemotherapy using an in vitro model. Our previous studies demonstrated inhibitory effects of PT in colon cancer formation and angiogenesis, as well as the underlying mechanisms responsible for the induction of apoptotic cancer cell death. ${ }^{23,24}$ In addition, we further demonstrated the synergistic effects of 5 -fluorouracil and PT on apoptosis and inhibition of human colorectal cancer cell proliferation and proposed the feasibility of combination chemotherapy for colon cancers. ${ }^{25} \mathrm{PT}$ is known to induce apoptosis via the cell death signaling pathway involving

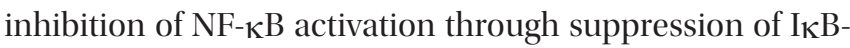
$\alpha$ phosphorylation. In chronic IBDs, excess cytokines produced by inflammatory cells activate NF- $\kappa$ B activity; multiple studies have consistently indicated that this elevated activity is a key cause of colonic inflammation and colon cancers. ${ }^{26}$

In 2012, Zhao et al. utilized dextran sulfate sodium to induce UC in mice and then administered PT by intraperitoneal injection. The authors found that PT ameliorated dextran sulfate sodium-induced colitis in mice through (1) inhibition of IкB- $\alpha$ phosphorylation; (2) suppression of p65 translocation; and (3) inhibition of p65 phosphorylation. ${ }^{27}$ Notably, phosphorylated $\mathrm{p} 65$ produced more pronounced effects on the modulation of target gene transcription, as compared to non-phosphorylated $\mathrm{p} 65 .^{28}$ Therefore, it is possible that coadministration of PT and balsalazide may inhibit the NF- $\mathrm{BB}$ signaling pathway and also strongly induce transcription, thus eliciting a more effective regulation of the target genes. The results of the present study showed that simultaneous exposure to PT and balsalazide produced pronounced inhibition of IאB- $\alpha$ phosphorylation, and suppression of $\mathrm{p} 65$ translocation and phosphorylation, as compared to cells treated with either agent alone.

Apoptotic cells are characterized by DNA fragmentation, cellular shrinkage, chromatic condensation, formation of apoptotic bodies, and activity of the caspase family of cysteine-dependent proteases. Caspase family regulation is particularly important in apoptosis. Degrees of apoptosis can be estimated from the activities of caspases cleaved during apoptotic events. ${ }^{29,17}$ Caspase-8 is known as an apoptosis initiator, since it cleaves and activates the pro-apoptotic protein, Bid. ${ }^{30}$ Furthermore, caspase-8 activates other caspases, such as caspase-3, which in turn cleaves other intracellular proteins and triggers apoptosis. The caspase-3, another representative caspase, has been known as an apoptotic terminal factor; it catalyzes the hydrolysis of a range of proteins, including lamin A, DNA fragmentation factors, $\alpha$-fodrin, and poly (ADP-ribose) polymerase, and drives an irreversible apoptotic process. ${ }^{31,32}$ Caspase- 3 also selectively cleaves the Asp-Ser sequence of human IкB- $\alpha$, thereby acting as a dominant inhibitor of NF- $\kappa B$ activity ${ }^{33,34}$ The present western blotting analysis found that exposure of HCT116 cells to both PT and balsalazide significantly lowered the levels of full length caspase, as compared to cells exposed to these agents individually. In the cells treated with the pan-caspase inhibitor (Z-VAD-FMK), this effect was reversed, confirming that the apoptotic cell death induced by simultaneous exposure to these agents might be caspase-dependent.

Bcl-2 suppresses cell death and is the gene responsible for mitochondrial membrane proteins; quantitative/qualitative changes in the Bcl-2 gene were first identified in lymphoma. Subsequent studies also identified Bcl-2 protein expression in nerves, skin, and epithelial cells of the digestive tract, rendering it a useful factor for determining cancer etiology or prognosis. ${ }^{35}$ Multiple studies have demonstrated that the Bcl-2 family and NF- $\kappa \mathrm{B}$ are closely associated with cell death pathways. Upon exposure to various stimuli activating 
NF- $\kappa$ B, for example inflammatory cytokines, hypoxia, and chemical stressors, NF- $\kappa \mathrm{B}$ translocates to the nucleus and initiates transcription of target genes. ${ }^{36,37}$ So far, the known target genes of NF- $\kappa \mathrm{B}$ include survivin, Bcl-xL, Bcl-2, cyclin D1, COX-2, MMP-9, and VEGF. ${ }^{38-43}$ Therefore, IкB- $\alpha$ and NF$\kappa \mathrm{B}$ are considered to be upstream controllers of the $\mathrm{Bcl}-2$ family, which is consistent with our results; PT and balsalazide (both NF-кB inhibitors) reduced Bcl-2 and Bcl-xL levels, thereby effectively inducing apoptotic cell death.

The present study demonstrated that exposure to both PT and balsalazide effectively inhibited proliferation of human colon cancer HCT116 cells by inhibiting NF- $\mathrm{KB}$ activity and inducing apoptotic cell death. These indicate that simultaneous administration of PT and balsalazide may provide a novel regimen for the treatment of colon cancer. However, additional in vitro and pre-clinical studies are required in order to shed further light on the detailed mechanisms underlying these effects.

\section{REFERENCES}

1. Sandborn WJ, Hanauer SB. Systematic review: the pharmacokinetic profiles of oral mesalazine formulations and mesalazine pro-drugs used in the management of ulcerative colitis. Aliment Pharmacol Ther 2003;17:29-42.

2. Sutherland L, Macdonald JK. Oral 5-aminosalicylic acid for induction of remission in ulcerative colitis. Cochrane Database Syst Rev doi:10.1002/14651858.CD000543.pub2. Published online 19 April 2006.

3. Feagan BG, Macdonald JK. Oral 5-aminosalicylic acid for maintenance of remission in ulcerative colitis. Cochrane Database Syst Rev doi:10.1002/14651858.CD000544.pub3. Published online 17 October 2012.

4. Shanahan F, Niederlehner A, Carramanzana N, Anton P. Sulfasalazine inhibits the binding of TNF alpha to its receptor. Immunopharmacology 1990;20:217-224.

5. Bantel H, Berg C, Vieth M, Stolte M, Kruis W, Schulze-Osthoff K. Mesalazine inhibits activation of transcription factor $\mathrm{NF}_{-} \kappa \mathrm{B}$ in inflamed mucosa of patients with ulcerative colitis. Am J Gastroenterol 2000;95:3452-3457.

6. Bork PM, Schmitz ML, Kuhnt M, Escher C, Heinrich M. Sesquiterpene lactone containing Mexican Indian medicinal plants and pure sesquiterpene lactones as potent inhibitors of transcription factor $\mathrm{NF}-\kappa \mathrm{B}$. FEBS Lett 1997;402:85-90.

7. Heinrich M, Robles M, West JE, Ortiz de Montellano BR, Rodriguez E. Ethnopharmacology of Mexican asteraceae (Compositae). Annu Rev Pharmacol Toxicol 1998;38:539-565.
8. Murphy JJ, Heptinstall S, Mitchell JR. Randomised double-blind placebo-controlled trial of feverfew in migraine prevention. Lancet 1988;2:189-192.

9. Schinella GR, Giner RM, Recio MC, Mordujovich de Buschiazzo P, Ríos JL, Máñez S. Anti-inflammatory effects of South American Tanacetum vulgare. J Pharm Pharmacol 1998;50:10691074 .

10. Hehner SP, Heinrich M, Bork PM, et al. Sesquiterpene lactones specifically inhibit activation of NF- $\kappa \mathrm{B}-\alpha$ by preventing the deg-

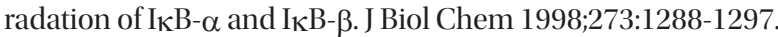

11. Oka D, Nishimura K, Shiba M, et al. Sesquiterpene lactone parthenolide suppresses tumor growth in a xenograft model of renal cell carcinoma by inhibiting the activation of NF- $\kappa$ B. Int J Cancer 2007;120:2576-2581.

12. Kim SL, Trang KT, Jeon BJ, et al. Synergistic effect of parthenolide in combination with 5 -fluorouracil in SW480 cells. Intest Res 2012;10:357-364.

13. Trang KT, Kim SL, Park SB, et al. Parthenolide sensitizes human colorectal cancer cells to tumor necrosis factor-related apoptosis-inducing ligand through mitochondrial and caspase dependent pathway. Intest Res 2014;12:34-41.

14. Zhang S, Ong CN, Shen HM. Critical roles of intracellular thiols and calcium in parthenolide-induced apoptosis in human colorectal cancer cells. Cancer Lett 2004;208:143-153.

15. Wen J, You KR, Lee SY, Song CH, Kim DG. Oxidative stressmediated apoptosis. The anticancer effect of the sesquiterpene lactone parthenolide. J Biol Chem 2002;277:38954-38964.

16. Vermeulen L, De Wilde G, Notebaert S, Vanden Berghe W, Haegeman G. Regulation of the transcriptional activity of the nuclear factor-кB p65 subunit. Biochem Pharmacol 2002;64:963-970.

17. Slee EA, Adrain C, Martin SJ. Serial killers: ordering caspase activation events in apoptosis. Cell Death Differ 1999;6:10671074 .

18. Yao J, Jiang Z, Duan W, et al. Involvement of mitochondrial pathway in triptolide-induced cytotoxicity in human normal liver L-02 cells. Biol Pharm Bull 2008;31:592-597.

19. Rhodes JM, Campbell BJ. Inflammation and colorectal cancer: IBD-associated and sporadic cancer compared. Trends Mol Med 2002;8:10-16.

20. Pinczowski D, Ekbom A, Baron J, Yuen J, Adami HO. Risk factors for colorectal cancer in patients with ulcerative colitis: a casecontrol study. Gastroenterology 1994;107:117-120.

21. Stolfi C, Pellegrini R, Franze E, Pallone F, Monteleone G. Molecular basis of the potential of mesalazine to prevent colorectal cancer. World J Gastroenterol 2008;14:4434-4439.

22. Bernstein CN, Nugent Z, Blanchard JF. 5-aminosalicylate is not chemoprophylactic for colorectal cancer in IBD: a population based study. Am J Gastroenterol 2011;106:731-736. 
23. Kim SL, Trang KT, Kim SH, et al. Parthenolide suppresses tumor growth in a xenograft model of colorectal cancer cells by inducing mitochondrial dysfunction and apoptosis. Int J Oncol 2012;41:1547-1553.

24. Kim SL, Lee ST, Trang KT, et al. Parthenolide exerts inhibitory effects on angiogenesis through the downregulation of VEGF/ VEGFRs in colorectal cancer. Int J Mol Med 2014;33:1261-1267.

25. Kim SL, Kim SH, Trang KT, et al. Synergistic antitumor effect of 5-fluorouracil in combination with parthenolide in human colorectal cancer. Cancer Lett 2013;335:479-486.

26. Grivennikov S, Karin E, Terzic J, et al. IL-6 and Stat 3 are required for survival of intestinal epithelial cells and development of colitis-associated cancer. Cancer Cell 2009;15:103-113.

27. Zhao ZJ, Xiang JY, Liu L, Huang XL, Gan HT. Parthenolide, an inhibitor of the nuclear factor- $\kappa \mathrm{B}$ pathway, ameliorates dextran sulfate sodium-induced colitis in mice. Int Immunopharmacol 2012;12:169-174.

28. Richmond A. NF- $\kappa$ B, chemokine gene transcription and tumour growth. Nat Rev Immunol 2002;2:664-674.

29. Hengartner MO. The biochemistry of apoptosis. Nature 2000;407:770-776.

30. Chiarugi V, Magnelli L, Cinelli M, Basi G. Apoptosis and the cell cycle. Cell Mol Biol Res 1994;40:603-612.

31. Baker SJ, Reddy EP. Modulation of life and death by the TNF receptor superfamily. Oncogene 1998;17:3261-3270.

32. Reed JC. Double identity for proteins of the Bcl-2 family. Nature 1997;387:773-776.

33. Estrov Z, Manna SK, Harris D, et al. Phenylarsine oxide blocks interleukin-1 $\beta$-induced activation of the nuclear transcription factor $N F-\kappa B$, inhibits proliferation, and induces apoptosis of acute myelogenous leukemia cells. Blood 1999;94:2844-2853.

34. Barkett M, Xue D, Horvitz HR, Gilmore TD. Phosphorylation of I $\mathrm{B}-\alpha$ inhibits its cleavage by caspase CPP32 in vitro. J Biol Chem 1997;272:29419-29422.
35. Korsmeyer SJ. Bcl-2 initiates a new category of oncogenes: regulators of cell death. Blood 1992;80:879-886.

36. Li L, Aggarwal BB, Shishodia S, Abbruzzese J, Kurzrock R. Nuclear factor- $\kappa \mathrm{B}$ and $\mathrm{I}_{\kappa} \mathrm{B}$ kinase are constitutively active in human pancreatic cells, and their down-regulation by curcumin (diferuloylmethane) is associated with the suppression of proliferation and the induction of apoptosis. Cancer 2004;101:2351-2362.

37. Liptay S, Weber CK, Ludwig L, Wagner M, Adler G, Schmid RM. Mitogenic and antiapoptotic role of constitutive NF- $\mathrm{B} / \mathrm{Rel}$ activity in pancreatic cancer. Int J Cancer 2003;105:735-746.

38. Kong R, Sun B, Jiang H, et al. Downregulation of nuclear factor$\kappa \mathrm{B}$ p65 subunit by small interfering RNA synergizes with gemcitabine to inhibit the growth of pancreatic cancer. Cancer Lett 2010;291:90-98.

39. Lee JU, Hosotani R, Wada M, et al. Role of Bcl-2 family proteins (Bax, Bcl-2 and Bcl-X) on cellular susceptibility to radiation in pancreatic cancer cells. Eur J Cancer 1999;35:1374-1380.

40. Lee MA, Park GS, Lee HJ, et al. Survivin expression and its clinical significance in pancreatic cancer. BMC Cancer 2005;5:127.

41. Tamm I, Kornblau SM, Segall H, et al. Expression and prognostic significance of IAP-family genes in human cancers and myeloid leukemias. Clin Cancer Res 2000;6:1796-1803.

42. Bai J, Sui J, Demirjian A, Vollmer CM, Jr., Marasco W, Callery MP. Predominant Bcl-XL knockdown disables antiapoptotic mechanisms: tumor necrosis factor-related apoptosis-inducing ligand-based triple chemotherapy overcomes chemoresistance in pancreatic cancer cells in vitro. Cancer Res 2005;65:23442352.

43. El-Rayes BF, Ali S, Ali IF, Philip PA, Abbruzzese J, Sarkar FH. Potentiation of the effect of erlotinib by genistein in pancreatic cancer: the role of Akt and nuclear factor- $\kappa$ B. Cancer Res 2006;66:10553-10559. 